\title{
Mídia / suporte e hipergênero: os gêneros textuais e suas relações
}

\section{Medium / support, and hypergenre: genre and its relationships}

\author{
Adair Bonini* \\ Universidade Federal de Santa Catarina \\ Florianópolis - Santa Catarina / Brasil
}

\begin{abstract}
RESUMO: Neste artigo, retomando trabalhos meus anteriores (BONINI, 2001, $2003,2005,2007)$, procuro discutir e propor alternativas para as distinçōes entre suporte, mídia e hipergênero, tendo em conta os conceitos de enunciado (BAKHTIN, 1953), discurso (FAIRCLOUGH, 2003) e gênero (dos estudos retóricos: BAZERMAN, 1994; SWALES, 1990; PARÉ; SMART, 1994). O artigo traz também uma proposta de quadro metodológico para a análise de gêneros, e uma aplicação do conceito de "relação genérica" em termos das mídias televisão e internet. PALAVRAS-CHAVE: Gênero textual, mídia, hipergênero, suporte de textos, discurso.
\end{abstract}

ABSTRACT: In this article, I pick up on some of my previous works (BONINI, 2001, $2003,2005,2007)$ in an attempt to discuss and propose alternatives to the distinctions among support, medium and hipergenre, adopting as theoretical basis the concepts of utterance (BAKHTIN, 1953), discourse (FAIRCLOUGH, 2003) and genre (from rhetoric studies: BAZERMAN, 1994; SWALES, 1990; PARÉ; SMART, 1994). This article also proposes a methodological framework to genre analysis, and applies the concept of "genre relationships" to TV and internet as instances of media.

KEYWORDS: Genre, medium, hypergenre, support of texts, discourse.

\section{Introdução}

Nos últimos anos, vários conceitos novos apareceram no contexto dos debates sobre gênero textual. O trabalho de Swales (2004), por exemplo, permite-nos visualizar a complexidade desse panorama, quando esse autor propõe que o termo constelação de gêneros passe a designar uma série de fenômenos: as hierarquias, as cadeias, os conjuntos e as redes de gêneros. Nesse

* adair.bonini@gmail.com 
agrupamento, o conceito de cadeia de gêneros é uma formulação a partir da proposição de sistema de gêneros de Bazerman (1994), o conjunto de gêneros é uma retomada da formulação realizada por Devitt (1991), e a rede de gêneros é um conceito inspirado na análise dialógica de Bakhtin (1953).

A proposição de conceitos nesse campo vem se dando sempre no sentido da ampliação do escopo social da noção de gênero. Não se entende mais que o gênero exista fora de relaçôes, e os estudiosos seguem construindo conceitos que procuram mapear essas relações, de modo que a questão do contexto passou a ser um ponto central nesse debate. Conforme salienta Bhatia (2004), o quadro dos estudos de gênero, da década de 90 em diante, vem se desenvolvendo no sentido de dar conta do contexto, segundo ele, notadamente em três linhas:

a) o estudo dos aspectos sociocognitivos dos gêneros, quanto ao desenvolvimento e à exploração de recursos genéricos (estudo dos sistemas de gêneros, por exemplo);

b) as análises multidimensionais e multiperspectivais de gêneros profissionais e institucionais (estudo da variação disciplinar e dos conflitos nos gêneros, por exemplo); e

c) o estudo da linguagem como discurso crítico, observando-se a linguagem como uma forma de controle social na e como interação social (estudo da relação entre discurso, mudança social e hegemonia, por exemplo).

Embora o debate caminhe no sentido da construção de consensos, como esse da contextualização do gênero, há ainda problemas bastante sensíveis a serem resolvidos em relação ao conjunto de conceitos que operam na área. $\mathrm{O}$ foco desse ensaio é um desses problemas: a relação entre os conceitos de suporte e mídia ${ }^{1}$ quanto ao modo como fazem circular os gêneros; sendo que, adianto,

\footnotetext{
${ }^{1}$ A palavra mídia, ou o conceito que ela encerra, envolve um conjunto complexo de termos: meio (sing.) e media (pl.); mídia (sing.) e mídias (pl.); médium (sing.) e médiuns (pl.), que é uma tradução de médium (sing.) e médias (pl.) do livro originalmente em francês de Debray (1991), termos posteriormente traduzidos como mídium (sing.) e mídiuns (pl.) em Maingueneau (1998a). Neste trabalho, conforme justificativa que aparece no decorrer do texto, opto pela distinção popular e corrente entre mídia (sing.) e mídias (pl.), desconsiderando o uso de mídia como coletivo de meios de comunicação. Para evitar um grande conjunto de termos diversos e uma leitura demasiadamente difícil e confusa, utilizo essa distinção mesmo para citar trabalhos de autores que utilizam outras opçôes terminológicas, embora elas possam aparecer nas citações de trechos desses trabalhos.
} 
vou defender que a mídia seja, nesse caso, entendida como elemento essencial e o suporte, apenas como um componente material da mídia.

Ao defender que a mídia seja o elemento-chave da circulação dos gêneros (e, portanto, da instauração da interação linguageira), é preciso, contudo, passar por outra distinção: entre gênero e hipergênero, termo já considerado em Bonini (2001, 2003, 2005). Em uma mídia circulam gêneros (um comercial na TV, por e exemplo), mas também gêneros compostos de outros gêneros (um telejornal, um programa de entrevistas, etc.). Não é incomum que se vejam os programas de TV, os sites de internet, etc., sendo mencionados como suportes.

$\mathrm{O}$ agrupamento de gêneros para compor uma unidade maior (o hipergênero) me sugere a proposição de um terceiro conceito: o de relação genérica; inspiração advinda também de Bazerman (1994). Um gênero não existe no vácuo, mas na relação com outros gêneros. Proponho, mais adiante, portanto, quatro tipos de relações genéricas: hipergenérica, midiática, em sistema e comunitária.

No texto que segue, faço, inicialmente, um debate sobre as noções de hipergênero, suporte e mídia. Em seguida, procuro estabelecer um ordenamento teórico-metodológico dos conceitos postos no campo, realizando, além disso, revisões de aspectos desses conceitos (mas principalmente do próprio conceito de gênero). Por último, a título de exemplificação do que me parece mais importante no quadro teórico proposto, procuro examinar as relações entre gênero, hipergênero e mídia na televisão e na internet.

\section{O gênero e sua mídia, mas não seu suporte}

O termo suporte (de texto ou de gênero) tem se tornado recorrente no debate teórico sobre linguagem nos últimos anos, ao menos no Brasil e em alguns países europeus (notadamente, na França). ${ }^{2}$ A definição de suporte é, contudo, uma questão ainda em aberto. Essa caracterizaçáo passa necessariamente pelo levantamento da relação entre suporte e gênero, para a qual foram esboçadas na literatura, até o momento, três explicaçóes.

$\mathrm{Na}$ primeira delas, Marcuschi (2003) concebe o suporte como um portador de textos, como "um locus físico ou virtual com formato específico

\footnotetext{
${ }^{2}$ Nos países anglófonos, utilizam-se apenas os termos latinos medium (sing.) e media (pl.) para fazer referência ao que denominamos, algumas vezes, suporte, outras vezes, midia.
} 
que serve de base ou ambiente de fixação do gênero materializado como texto" (p. 11). O autor entende que existam duas formas de suporte: o convencional (elaborado exatamente com o objetivo de portar textos) e o incidental (que apresenta outros objetivos, mas eventualmente pode servir como base de fixação de textos). Esse ensaio de Marcuschi tem o mérito de ter aberto o debate sobre o suporte de forma muito bem sucedida. Não obstante a esse papel de "desbravador" (ou talvez até mesmo em função disso), ele não traz uma abordagem muito aprofundada ou consistente da relação entre gênero e suporte. $\mathrm{O}$ autor estabelece uma fronteira bastante rígida entre o suporte como elemento material e o gênero como elemento simbólico. Além disso, o ensaio aponta um número excessivo de objetos relacionados ao funcionamento dos gêneros (serviço, canal, instituição, grandes continentes) sem, contudo, apresentar uma elaboração teórica de fundo que os viabilize como objetos de pesquisa.

A segunda posição com relação a esse tema encontra-se no artigo de Bonini (2005), que é uma continuação de trabalhos anteriores (BONINI, 2001, 2003). Neste artigo, entendo o suporte também como um portador de textos, mas defendo a tese da existência de duas formas de suporte: os físicos (o álbum, o outdoor, etc.) e os convencionados (o jornal, a revista, etc.). Essa posição (que revejo no presente artigo) pressupõe, conforme discutido em Bonini (2003), a existência de um contínuo que vai do gênero (como unidade da interação dialógica ${ }^{3}$ ) ao suporte em sua forma mais característica (como portador físico). Em meio a esses dois pontos extremos, haveria a ocorrência de elementos hibridos que seriam, ao mesmo tempo, um gênero formado por outros gêneros (um hipergênero) e um suporte, sendo exemplos, entre outros, o jornal, a revista, o site.

Távora (2008) aproveita parcialmente essa tese para propor sua explicação de suporte. Para ele, o suporte corresponde a um elemento material responsável pela atualização de gêneros, mas que apresenta uma série de elementos da ordem do convencional (a diagramação no jornal, por exemplo). Apesar de incorporar essa premissa de que há certa sobreposição entre suporte e gênero, seu trabalho centra-se em uma manutenção da fronteira entre o

\footnotetext{
${ }^{3} \mathrm{O}$ termo dialógico é aqui entendido como relacionado ao conceito de dialogia de Bakhtin (1953). Para esse autor, o diálogo é a propriedade fundamental da linguagem, uma vez que ela existe como uma cadeia ininterrupta de enunciados e que cada enunciado da cadeia consiste sempre em uma reação-resposta ativa a outro enunciado.
} 
material (físico), representando o suporte, e o convencional (simbólico), representando o gênero.

$\mathrm{O}$ autor propõe um conceito de suporte dividido em três componentes. O primeiro deles é a matéria (caracterizada como um plano físico, em contraposição a um plano linguístico e simbólico), que se compõe também de três processos: o registro (o arquivamento de dados, por exemplo, em um $\mathrm{CD}$ ), a atualização (a produção de gêneros sem necessariamente haver um registro, por exemplo, no rádio) e o acesso (as formas de interação possibilitadas pelo suporte, por exemplo, unilateral na televisão). O segundo componente do suporte em Távora (2008) é a sua forma, que corresponde a uma especificação do terceiro elemento da materialidade, o acesso. A forma do suporte se constitui em função de dois fatores:

a) as distintas possibilidade de atualização de linguagem verbal e não verbal; b) diferentes níveis de interatividade ditados pelo fluxo comunicativo e sua divisão, que interfere na recepção, no tempo e no modo de resposta, portanto na responsividade do co-enunciador ou coenunciador (p. 127).

Segundo essa lógica, as possibilidades de atualização dizem respeito, por exemplo, ao modo como o gênero se materializa no jornal em função dos padrões de diagramação. Uma foto, nesse caso, figura na página do jornal tanto como gênero autônomo quanto como parte de outros gêneros ali atualizados. Já os niveis de interatividade dizem respeito, entre outros, às possibilidades espaciais e temporais do suporte. O outdoor, por exemplo, oferece um tempo mínimo de visualização ao destinatário, e isso tem impacto na atualização do gênero nesse suporte.

O terceiro componente do conceito de suporte proposto por Távora é a interação. Ele afirma que o suporte é uma ferramenta sócio-técnica "elaborada para estabelecer processos interativos" (p. 157). Defende a tese de que o suporte, até o momento desconsiderado nas análises de gênero, deveria ocupar o primeiro plano da ordem metodológica proposta por Bakhtin e Volochínov (1929, p. 129) que consiste em três níveis: a) as formas e os tipos de interação; b) as formas das enunciações; e c) as formas da língua.

Esse terceiro elemento do conceito proposto por Távora (2008), contudo, ficaria mais bem arranjado se fosse entendido como um princípio de funcionamento, uma vez que não pode ser visto, de fato, como um componente ou uma parte do suporte como entidade ontológica. O próprio 
autor parece estar tratando, nesse trecho do trabalho, mais de um aspecto da metodologia de pesquisa de gêneros do que da definição de suporte propriamente. ${ }^{4}$

O termo suporte encontra sua sustentação teórica inicial na obra de Debray (1991). Esse autor, contudo, relaciona esse conceito com o de mídia, ${ }^{5}$ o que representa um segundo ponto de contenda nessa discussão.

Debray (1991) se inspira em McLuhan (1964) para explicar o suporte como um elemento tecnológico responsável por revoluçōes históricas nas práticas comunicativas e, portanto, na própria maneira de se conceber a realidade social em cada fase da história humana. Nesse sentido é que o surgimento da imprensa, por exemplo, levou à eliminação de toda uma classe de profissionais (os copistas) e produziu uma diminuição do poder da Igreja Católica, uma vez que a bíblia (como livro sagrado) gradativamente passou a ser de acesso massificado, não havendo mais a necessidade da mediação institucional. Além disso, a cópia manual de livros possibilitava uma forma de controle ideológico por parte da Igreja Católica, e esse controle se enfraqueceu com a imprensa e a popularização do livro, possibilitando a ascensão de ideais até então reprimidos, o que deu origem, por exemplo, à reforma protestante. Para Debray (1991), o surgimento do novo suporte produz, portanto, toda uma reconfiguração das relaçôes de poder na sociedade do século XVI.

McLuhan (1964), ao se referir ao meio (de comunicação), não faz uma distinção precisa entre as tecnologias de comunicação e as demais inovações tecnológicas. Nesse sentido, portanto, ele afirma que "a 'mensagem' de qualquer meio ou tecnologia é a mudança de escala, cadência ou padrão que esse meio ou tecnologia introduz nas coisas humanas" (p. 22) e, logo em seguida, cita o surgimento da estrada de ferro como responsável pela aceleração e ampliação das funçôes humanas anteriores, "criando tipos de cidades, de trabalho e de lazer totalmente novos".

Essa imprecisão conceitual também aparece em Debray (1991), ao estabelecer como objeto da Midiologia as "mediaçôes pelas quais 'uma ideia se

\footnotetext{
${ }^{4}$ Além dos trabalhos apontados (MARCUSCHI, 2003; BONINI, 2005; e TÁVORA, 2008), pode-se citar também a exposição de Maingueneau (1998a) que tem sido mencionada na literatura. Sua abordagem, contudo, difere pouco da de Debray (1991), motivo pelo qual não está sendo considerada aqui.

${ }^{5}$ Como expliquei em nota de rodapé anterior, estou uniformizando as distintas terminologias dos vários autores que tratam do assunto, ao empregar apenas os termos mídia (sing.) e mídias (pl.).
} 
torna força material'", das quais os meios de comunicação de massa seriam "apenas um prolongamento particular, tardio e invasor" (p. 14). Com base nesse enquadramento, o autor concebe a mídia não como um objeto específico, mas como um processo, uma vez que ela designa, nesse caso, "o conjunto, técnica e socialmente determinado, dos meios simbólicos de transmissão e circulação" (p. 15). A imprecisão conceitual se torna visível, por exemplo, no capítulo sobre o suporte, no qual ele se refere ao livro como uma mídia, pronunciando-se nos seguintes termos: "Esse médium fermentou durante quase um século, antes de revelar que uma nova técnica de comunicação veicula uma nova moral intelectual [...]" (p. 217 - negrito nosso). O texto não deixa claro em que medida o livro é um suporte e / ou uma mídia.

Em uma comparação entre os trabalhos de McLuhan (1964; McLUHAN; FIORI, 1967) e Debray (1991), ambos tratam do mesmo fenômeno por termos distintos: meio para um, suporte para o outro. Não fica muito evidente qual é o lugar do suporte na arquitetura conceitual desse segundo autor, uma vez que médium e suporte se sobrepõem e, ao mesmo tempo, se distanciam. De modo geral, entretanto, é possível interpretar que o suporte seja por ele entendido como um componente do médium, o que pode se revelar uma lógica bastante produtiva no debate sobre gêneros, e é a que defendo aqui. ${ }^{6}$

Nas discussões sobre a relação entre suporte e gênero, todos os três trabalhos apontados acima (MARCUSCHI, 2003; BONINI, 2005; TÁVORA, 2008) excluem o componente mídia. Essa relação do suporte como parte da mídia, que aparece pelo menos esboçada em Debray (1991), pode, contudo, ser uma forma de se resolver alguns problemas conceituais. Se o livro preenche perfeitamente o que se tem entendido por suporte, não me

\footnotetext{
${ }^{6}$ A respeito dessa relação entre suporte e mídia, Debray (1991) assim se pronuncia: "É possível fazer entrar aí [no médium] instituiçôes (a escola), objetos técnicos (aparelho de rádio, tela de cinema, tubo catódico), suportes materiais (papel, tecido, fita magnética, tijolo), códigos sociais (gramática, sintaxe), órgãos do corpo (laringe, cordas vocais), modos gerais de comunicação (oral, escrito, impresso, audiovisual, informática). [...] Ainda que nos limitemos exclusivamente à comunicação verbal, 'simbólica' e não 'indicial', aquela que, portanto, exige colocação em código e decodificação, o termo médium poderá aplicar-se tanto à linguagem natural utilizada (inglês ou latim), como ao órgão físico de emissão e apreensão (voz que articula, mão que traça sinais, olho que decifra o texto), ao suporte material dos traços (papel ou tela), ao processo técnico de coleta de dados e reprodução (impresso, eletrônico): ou seja, no mínimo quatro acepções" (p. 18 - negritos meus).
} 
parece ocorrer o mesmo com o rádio, a televisão ou mesmo a internet. É comum que se interprete a tela como o suporte correspondente ao computador eà televisäo. Essa perspectiva, contudo, contempla apenas o suporte como elemento do processo de leitura - como tem sido tratado por Chartier (1997) -, não levando em consideração que estão envolvidos aí muitos outros meios tecnológicos de mediação da enunciação. Cabos, ondas eletromagnéticas, disco rígido, são suportes que compõem a televisão e a internet que, como tal, são a meu ver mídias.

Em uma pesquisa realizada no Google e no Google Acadêmico, no dia 18 de setembro de 2008, procurei levantar a ocorrência dos termos mídia e suporte. Em relação a diversos elementos que poderiam ser recobertos por esses termos (tais como livro, televisão, internet), informei como item de busca: "o(a) Xé uma mídia" e "o(a) Xé um suporte". Esse levantamento [QUADRO 1] evidenciou, por um lado, que ambos os termos recobrem praticamente os mesmos objetos (embora não na mesma ordem) e, por outro, que o termo mídia apresenta um número maior de ocorrências. A proporção também se mostra similar tanto no Google (de registro, em tese, mais popular, dada a amplitude dos itens indexados) e quanto no Google Acadêmico (de registro mais formal e teórico).

\section{QUADRO 1}

Ocorrências dos termos mídia e suporte no Google e no Google Acadêmico

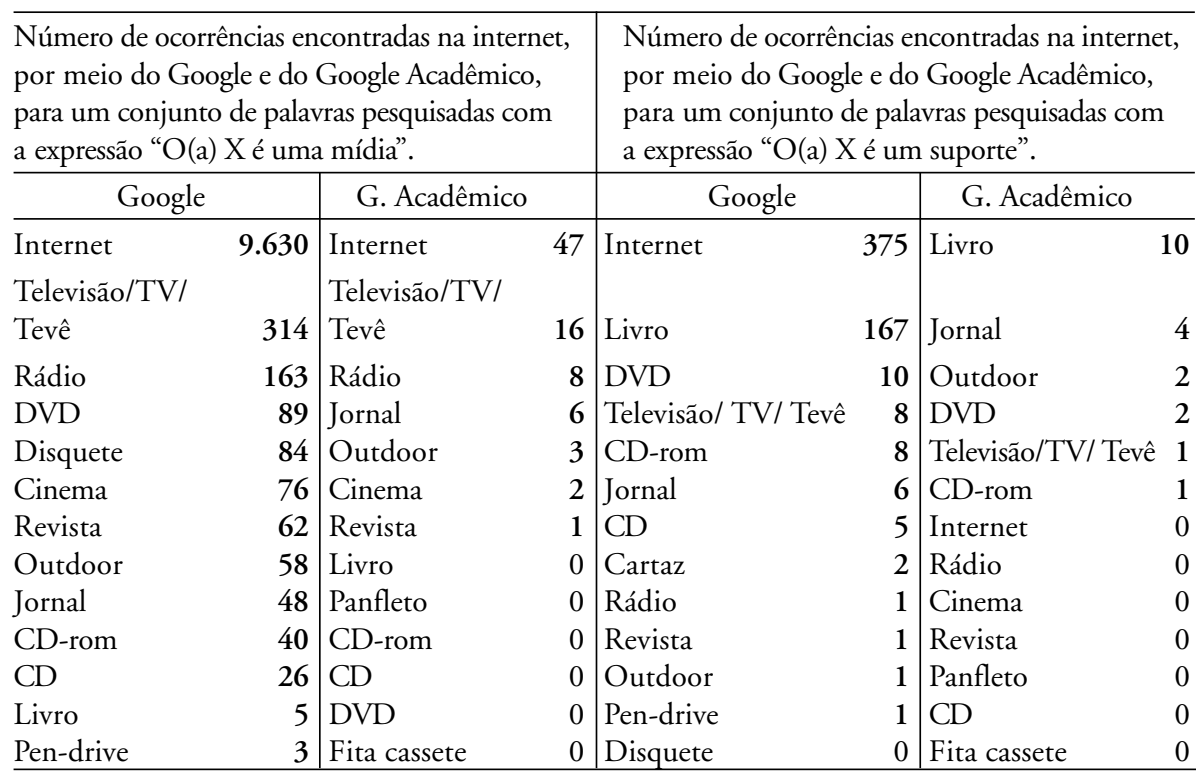




\begin{tabular}{|c|c|c|c|c|c|c|}
\hline Telefone & 2 & Disquete & 0 & Cinema & 0 & Disquete \\
\hline E-mail/ email & 2 & Pen-drive & 0 & Telefone & 0 & Pen-drive \\
\hline Panfleto & 1 & Telefone & 0 & E-mail/ email & 0 & Telefone \\
\hline Cartaz & 1 & E-mail/ email & 0 & Panfleto & 0 & E-mail/ email \\
\hline Fita cassete & 0 & Cartaz & 0 & Fita cassete & 0 & Cartaz \\
\hline
\end{tabular}

A opção pelo termo mídia, portanto, representa um ganho se se leva em conta esse uso social. $\mathrm{O}$ meio social acadêmico tem a prerrogativa de criar novos termos, dada a especificidade do trabalho aí realizado. Cabe perguntarse, contudo, qual ganho pode haver na criação de um novo termo, como o de suporte, para recobrir os mesmos objetos já cobertos por um termo criado anteriormente? Não há ganho explicativo evidente, ainda mais se pensarmos que tanto o conceito de mídia quanto o de suporte permanecem pouco claros no debate teórico.

Minha opção, nesse caso, é por se manter o termo mídia (plural: mídias), deslocando o termo suporte para as tecnologias de registro, armazenamento e transmissão envolvidas nessas mídias. Essa escolha ocorre também em meio a diversas opçōes alternativas para o próprio termo mídia: 1) por influência da Língua Inglesa na qual se utilizam os termos latinos medium (sing.) e media (pl.), houve, no português do Brasil, uma tendência de se utilizar os termos meio (sing.) e media (pl.); 2) no uso popular corrente, conforme está inclusive dicionarizado em Houaiss (2001), formou-se, em função da prevalência do segundo termo em alguns meios sociais e da forma como é pronunciado em inglês, a distinção entre mídia (sing.) e mídias (pl.), embora, de modo geral, o termo mídia com o sentido de conjunto de meios de comunicação ainda continue corrente, existindo, portanto, uma ambiguidade terminológica; 3) Debray (1991) utilizou, no original francês de seu livro, os termos médium (sing.) e médias (pl.), que foram traduzidos para o português como médium (sing.) e médiuns (pl.); e 4) na publicação brasileira do livro de Maingueneau (1998a), os termos da tradução brasileira de Debray foram retraduzidos como mídium (sing.) e mídiuns (pl.), conforme justificativa dos tradutores, para manter a distinção pretendida por Debray e para evitar confusão com a "forma já dicionarizada" médium que, segundo eles, refere-se a outro conceito. Os termos vão se proliferando a ponto de dificultar a compreensibilidade de qualquer abordagem ao tema, de modo que há, nesse caso, vantagens em se manter os termos da linguagem cotidiana corrente (mídia / mídias), minha escolha nesta exposição.

Em vez de fazer uma história das idéias como faz Debray (1991) ao inspirar-se nesse campo dos estudos históricos, meus apontamentos aqui vão 
no sentido de se pensar como o termo mídia se junta a outros termos para compor a explicação de um plano da linguagem. Diferentemente desse autor que vê uma mídia como um processo de difusão e assimilação social de uma ideia, entendo, incorporando parte da reflexão de Távora (2008) sobre suporte (mas substituindo suporte por mídia), que uma mídia seja um processo tecnológico de mediação da interação linguageira. Uma mídia estabelece coordenadas (processos de edição, relações espaciais e temporais particulares entre interlocutores, etc.) às quais o gênero se ajusta, de modo que as várias versões de uma mesma notícia na televisão, no rádio, no jornal e na internet são coisas relativamente distintas em função do tipo de mediação linguageira a que estão sujeitas. Em oposição ao gênero, que é uma unidade da interação linguageira, a mídia é um elemento contextualizador no interior do qual o gênero circula. Mas não se trata de um elemento inócuo em relação ao gênero, uma vez que é a mídia que determina as coordenadas de cada gênero que nela circula.

Dentro do enquadramento que estou esboçando, os três termos aqui tratados podem ser assim definidos:

a) gênero - unidade da interação linguageira que se caracteriza por uma organização composicional, um modo característico de recepção e um modo característico de produção. Pode ser de natureza verbal, imagética, gestual, etc. Como unidade, equivale ao enunciado bakhtiniano; ${ }^{7}$

b) mídia - tecnologia de mediação da interação linguageira e, portanto, do gênero como unidade dessa interação. Cada mídia, como tecnologia de mediação, pode ser identificada pelo modo como caracteristicamente é organizada, produzida e recebida e pelos suportes que a constituem; e

c) suporte - elemento material (de registro, armazenamento e transmissão de informação) que intervém na concretização dos três aspectos caracterizadores de uma mídia (suas formas de organização, produção e recepção).

\footnotetext{
${ }^{7} \mathrm{O}$ conceito de enunciado em Bakhtin (1953, p. 279-286) está assentado em duas características: a) a alternância dos sujeitos do discurso, que consiste em um modo dixi de transferência da fala ao outro; e b) a conclusibilidade, que consiste em uma inteireza de sentido dotada de expressividade autoral e "determinada por três elementos (ou fatores) intimamente ligados no todo orgânico do enunciado: 1) exauribilidade do objeto e do sentido; 2) projeto de discurso ou vontade de discurso do falante; 3) formas típicas composicionais e de gênero do acabamento" (p. 281).
} 
Em geral, as mídias apresentam um conjunto de suportes encadeados na forma de um sistema. Na televisão, por exemplo, há o microfone, a câmera, a mesa de edição, os suportes de transmissão (ondas eletromagnéticas, cabo, sinal de satélite, etc.), e o aparelho de televisão. Já o DVD, como mídia, é composto dos seguintes suportes: a embalagem do disco, o disco, o aparelho de DVD e a televisão, que fazem circular os (hiper)gêneros que ali são possíveis (filme de aventura, documentário, show, etc.).

Mesmo reconhecendo a existência do suporte, não se pode dizer que ele seja o elemento mais diretamente relacionado ao gênero como unidade da interação. Em sentido abrangente, os termos mais importantes e usuais para se caracterizar o processo de interação são gênero e mídia. O termo suporte só é relevante em uma análise mais pormenorizada de uma mídia específica. Podemos dizer, desse modo, que a interação se faz por meio de gêneros e que esses gêneros circulam em mídias.

Além das relações com a mídia (comentadas até aqui), o gênero está sujeito também a uma série de outras relações contextualizadoras, as quais estou aqui denominando "relações genéricas" e que são o tema da próxima seção. Proponho um conceito específico de gênero, ao proceder a uma releitura do conceito da tradição sócio-retórica.

\section{Um quadro conceitual para a análise de gêneros}

Paré e Smart (1994) apresentam a seguinte questão como fio condutor de seu artigo: "Quando vistos como ação social, quais são, além dos textos, os elementos constituintes observáveis de um gênero?” (p. 146 - tradução minha). Eles propõem que esses elementos observáveis sejam regularidades de quatro tipos: 1 ) as textuais; 2 ) as dos papéis sociais; 3 ) a dos processos de composição; e 4) as das práticas de leitura. $\mathrm{Na}$ explicação de gênero que aqui esboço (no primeiro dos três planos que compóem a FIG. 1: do gênero, do discurso, e da estrutura social), procuro me apoiar em três dos aspectos apontados por esses autores (regularidades textuais, de composição e de leitura), procedendo, além disso, a um ajuste no interior da perspectiva sócio-retórica, ao abandonar a noção de propósito.

Os trabalhos que vêm o gênero como ação social incorporam o pressuposto básico de que o gênero realiza um propósito comunicativo, um conceito bastante problemático do ponto de vista epistemológico, como já apontaram Askenhave e Swales (2001). Esses autores mostram que um gênero pode ter diversos propósitos e que eles ainda variam de acordo com o foco de 
observação. Pode-se acrescentar a isso o fato de que o propósito é um elemento de ordem subjetiva, ao qual o pesquisador não tem acesso direto. Nesse sentido, opto aqui por estabelecer como base do gênero não a realização de um propósito, mas a de uma prática social que seria um meio termo entre os conceitos de prática social de Fairclough (2003) e de projeto enunciativo de Bakhtin (1953). A prática social em Fairclough diz respeito a um conjunto de ações mais ou menos reconhecíveis em determinado meio social (sendo exemplos, as práticas de ensino e as práticas de gerenciamento em instituições educacionais). O conceito de projeto enunciativo de Bakhtin (1953), por sua vez, diz respeito ao que o sujeito procura construir em uma enunciação como resposta a enunciados passados ou futuros. Nas palavras de Furlanetto (2007):

[...] na enunciação, ao formular sua expressão, o sujeito-locutor estabelece um projeto enunciativo: o que enuncia diz respeito, generalizadamente, a um uso efetivo nas enunciações de outrem, e não a uma mera extração delas de um arquivo lexicográfico, tal como um dicionário ou uma gramática (p. 212).

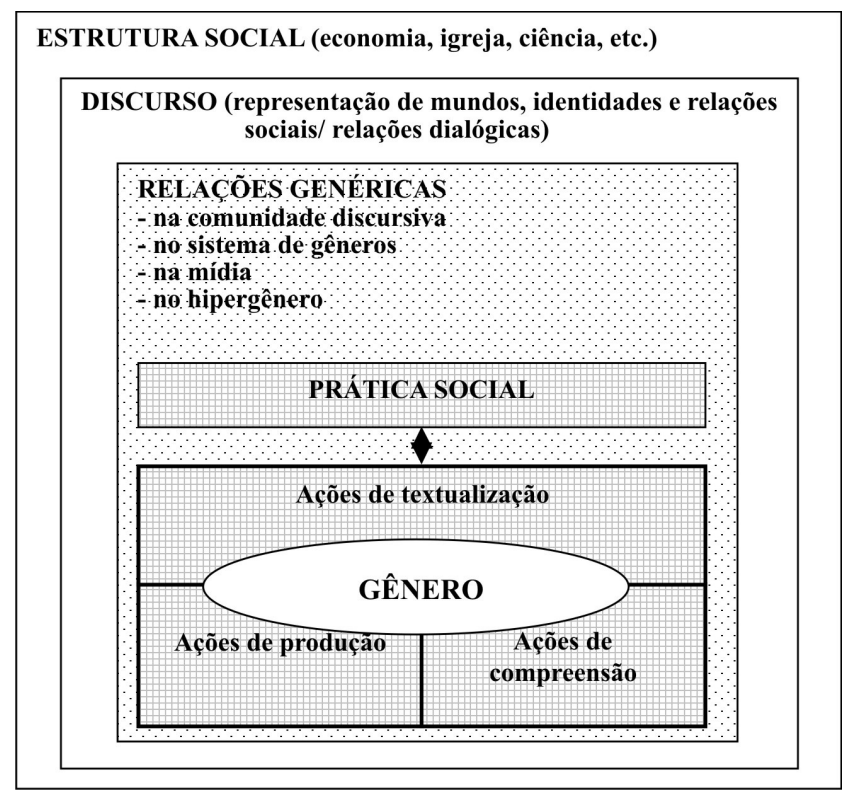

FIGURA 1: planos da análise de gêneros e da análise de discurso

Considerando ambas as formulações, a de Fairclough é muito abrangente e de difícil delimitação em uma análise de gênero, e a de Bakhtin 
é muito específica, já que é centrada no ato individual, não permitindo que se determine, de imediato, o que mais costumeiramente se produz como prática por meio de um gênero. O que estou chamando de prática social é o resultado das açôes realizadas em um gênero: de textualização, de produção e de compreensão. Em uma notícia, por exemplo, a prática social, à primeira vista, é o relato de um acontecimento recente, envolvendo ações de textualização (como a organização em pirâmide invertida), de produção (como as de apuração do fato), e de compreensão (a exemplo da leitura da manchete e do lide como meio de se tomar a decisão sobre se se deve ler ou não o restante do texto). As práticas variam de acordo com o olhar que se lança sobre elas: em vez de relato de um acontecimento recente, uma notícia pode ser uma pressão sobre o governo, realizada por determinados grupos sociais. O conjunto dessas práticas sociais também pode ser chamado de prática social ao modo de Fairclough (2003): por exemplo, a prática econômica, educacional, administrativa. ${ }^{8}$ A prática social de um gênero é o que se pode depreender como resultado das ações nele realizadas (de textualização, compreensão e produção).

O postulado que guia as formulações expostas nesta seção é o de que o gênero, como unidade da interação linguageira, está sempre imerso em uma série de relações contextualizadoras que lhe são constitutivas. As primeiras, em uma perspectiva ascendente, são as relaçôes genéricas que correspondem a interfaces estruturais no nível da própria interação, uma vez que incidem diretamente sobre o gênero e, portanto, sobre a dinâmica dialógica. Tais relações dizem respeito a quatro componentes:

a) o hipergênero - os gêneros, por vezes, são produzidos em agrupamento, compondo uma unidade de interação maior (um grande enunciado) que estou chamando de hipergênero. ${ }^{9} \mathrm{O}$ jornal, nesse sentido, é um hipergênero,

\footnotetext{
${ }^{8}$ Essa reflexão começou a ser formulada em Bonini (2007).

${ }^{9}$ Minha explicação de hipergênero difere da de Maingueneau (1998b, 2004), uma vez que ele o descreve como um princípio organizador superior ao gênero, enquanto eu (BONINI, 2001, 2003, 2005) proponho que o hipergênero seja entendido como um gênero de um nivel superior. Segundo esse autor (MAINGUENEAU, 2004), hipergêneros são: 'categorizaçôes como 'diálogo', 'carta', 'ensaio', 'jornal', etc., que permitem formatar o texto. Não se trata, como o gênero de discurso, de um dispositivo de comunicação historicamente definido, mas de um modo de organização textual com restrições fracas, que encontramos em épocas e em lugares diversos e no interior do qual encenaçôes de fala diversificadas podem se desenvolver" (p. 54).
} 
uma vez que ele responde às características propostas por Bakhtin (1953) para caracterizar o enunciado [QUADRO 2 abaixo]. Uma notícia é produzida em um jornal como parte de um grande enunciado, de modo que ela se relaciona necessariamente com os demais gêneros produzidos (com a chamada, com o editorial, com os artigos, etc.). Todo hipergênero, como o jornal, a revista, o site, apresenta um sistema de disposição dos enunciados que envolve gêneros organizadores (sumário, introdução, editorial, chamada, etc.) e gêneros de funcionamento (notícia, romance, tratado, entrevista, etc.) $;^{10}$

\section{QUADRO 2}

Características do enunciado (BAKHTIN, 1953, p. 281) aplicadas ao jornal

\begin{tabular}{l|l}
\hline $\begin{array}{l}\text { Características } \\
\text { do enunciado }\end{array}$ & \multicolumn{1}{c}{ Aplicação dessas características ao jornal } \\
\hline $\begin{array}{l}1 \text { - alternância dos } \\
\text { sujeitos do discurso }\end{array}$ & $\begin{array}{l}\text { O jornal apresenta um modo dixi (sua própria constituição, por } \\
\text { exemplo, com primeira e última página) que assinala a alternância } \\
\text { de enunciados (de edição para edição) e dá a deixa para que o } \\
\text { outro se pronuncie em relação ao seu conteúdo. }\end{array}$ \\
\hline $\begin{array}{l}\text { A) "exauribilidade } \\
\text { do objeto e do sentido" }\end{array}$ & $\begin{array}{l}\text { A equipe que produz o jornal expressa todo o conteúdo que quer ou } \\
\text { pode expressar na edição. Esse conteúdo, por sua vez, funciona } \\
\text { como uma unidade de sentido que pode ser alvo de réplica, de } \\
\text { modo que alguém pode afirmar, por exemplo: "Gostei da edição } \\
\text { de ontem do jornal X". }\end{array}$ \\
\hline $\begin{array}{l}\text { B) "projeto de discurso } \\
\text { ou vontade de discurso } \\
\text { do falante" }\end{array}$ & $\begin{array}{l}\text { Embora compartilhado entre muitos sujeitos e não passível de } \\
\text { especificação, há um intuito na produção do jornal. Do mesmo } \\
\text { modo como ocorre com outros enunciados coletivos, a exemplo de } \\
\text { um filme, de um espetáculo, há, no caso do jornal, uma hierarquia } \\
\text { de enunciadores. Sendo assim, alguns têm mais poder e espaço na } \\
\text { construção do todo do que outros. No caso de um filme, é } \\
\text { geralmente o diretor; no do jornal, os editores. }\end{array}$ \\
\hline $\begin{array}{l}\text { C) "formas típicas } \\
\text { composicionais e de } \\
\text { gênero do acabamento" }\end{array}$ & $\begin{array}{l}\text { O jornal apresenta uma organização genérica, composta } \\
\text { principalmente de cabeçalho, chamadas, expediente, editorial, carta } \\
\text { do leitor e cadernos. Essa organização, por sua vez, cria um espaço } \\
\text { de circulação para outros gêneros. }\end{array}$ \\
\hline
\end{tabular}

${ }^{10} \mathrm{Em}$ Bonini (2001), chamei esses gêneros organizadores e de funcionamento de gêneros presos e livres. 
b) a mídia - como forma tecnológica material de mediação da interação linguageira, a mídia constitui-se de um ou mais suportes e apresenta uma forma característica de organização, produção e recepção. Diferentemente do hipergênero, a mídia não é um grande enunciado, mas um continente para os enunciados. Ela dispóe os sujeitos e suas locuções numa determinada ordem espacial e temporal, fazendo o mesmo com os interlocutores. Por vezes, elas também apresentam gêneros organizadores (como é o caso das vinhetas nos canais de televisão). Gêneros e hipergêneros se ajustam às formas de produção e recepção possibilitadas pela mídia. $O$ hipergênero pode preencher o todo de uma mídia (como é o caso do jornal, da revista), mas ele também pode ser apenas um grande enunciado em meio a outros em determinada mídia (a exemplo do telejornal e do programa de entrevistas na televisão);

c) o sistema de gêneros - os gêneros também podem ser vistos como elementos de uma sequência de práticas e ações sociais. Conforme explica Bazerman (1994), em um sistema ordenado sequencialmente, um gênero cria condições para existência de outro. Desse modo, a própria mídia se realiza por meio da execução de pelo menos um sistema de gêneros (na televisão, por exemplo, existem sistemas de gêneros que possibilitam a produção, a edição e a transmissão de programas); e

d) a comunidade discursiva - os gêneros, em uma comunidade discursiva, conceito proposto por Swales (1990), estão a serviço de uma hierarquia de membros que, juntos, realizam um conjunto de práticas sociais também hierarquizadas. Em uma comunidade discursiva existem gêneros reguladores das práticas (os manuais, os regimentos, etc.) e mecanismos de aferição de poder e de determinação das identidades (prêmios, insígnias, títulos, ritos de passagem, etc.) (BONINI, 2010b). As práticas sociais de uma comunidade discursiva se realizam por meio de gêneros, hipergêneros, mídias, e sistemas de gêneros, embora esses últimos não necessariamente existam nos limites de uma comunidade.

Cada uma dessas formas de relação genérica (hipergenérica, midiática, sistêmica e comunitária) representa um modo de abordar, cientificamente, os gêneros. O desenho da pesquisa pode contemplar mais de um desses conjuntos de relaçôes, dependendo da complexidade do gênero e da coleta, e do tempo disponível para a realização do estudo. 
Depois das relações genéricas, vêm, em seguida, as relações no plano do discurso. Os gêneros são criações do discurso, mas as práticas sociais realizadas pelos gêneros reconfiguram ou criam discursos, vistos aqui como as representaçôes que caracterizam os estados dos mundos, os seres sociais (as identidades) e os tipos de práticas e ações permitidas (as relações sociais). Conforme Fairclough (2003), um "discurso é uma forma particular de representar alguma parte (física, social ou psicológica) do mundo" (p. 17 - tradução minha). Ao mesmo tempo em que é representação, o discurso pode ser visto também como a cadeia ininterrupta de relaçôes dialógicas que se realiza na sociedade.

Por último, podem-se enfocar as relações no plano da estrutura social. As instituições (como a igreja, a economia e a ciência) constituem tanto os discursos quanto as práticas sociais e são, ao mesmo tempo, por esses constituídas. Tanto as relaçōes entre gênero textual e discurso quanto as relaçōes entre discurso e estrutura social são alvo de uma dupla estruturação nos moldes do que propõe Giddens (1984): a estrutura constitui a ação e, ao mesmo tempo, a ação constitui a estrutura.

Se observada de uma perspectiva ascendente (da unidade para o todo), a FIG. 1 (do início dessa seção) mostra o modo como a análise de gêneros pode ser realizada. O estudo dos gêneros, centrado nas práticas sociais e nas açôes de textualização, produção e compreensão de enunciados, possibilita uma forma de entendimento dos discursos e das estruturas sociais que são tomados, nesse caso, como horizontes de expectativa. A análise crítica de gêneros é um resultado do quanto a pesquisa de um gênero específico pode se aproximar de uma reflexão sobre as assimetrias nas identidades e as relações sociais. Silva (2007), por exemplo, em um estudo do gênero entrevista ping-pong nas revistas Veja, IstoÉ e Carta Capital, consegue, como ponto de chegada da análise, mostrar aspectos dos diferentes funcionamentos ideológicos dessas publicações. Bonini (2010b) estuda os gêneros que compõem a prática do concurso público para professor universitário, observando que tipo de identidade e relações sociais estão em jogo.

A FIG. 1 também pode ser lida por uma perspectiva descendente e, nesse caso, pode-se visualizar a realização da análise crítica dos discursos. No estudo das relações de poder assimétricas e de exploração criadas na estrutura social, o gênero (sua prática social e ações) e as relações genéricas assumem o papel de delimitadores da amostra analisada. Pode-se escolher como contexto da pesquisa, por exemplo, uma revista feminina no seu todo, como faz Figueiredo (1995), ou um gênero específico, por exemplo, a reportagem em Magalhães (2004). Ao explorar, de forma mais enfática, esse papel do gênero como um 
caracterizador da amostra, a análise crítica do discurso pode trazer uma contribuição cada vez mais significativa para o entendimento do gênero. Análise crítica de discurso e de gênero são abordagens completares.

Na próxima seção, retomo o tema das relaçôes genéricas (apenas duas delas) para aprofundar o tratamento dos termos centrais neste artigo: mídia e hipergênero.

\section{Relações genéricas na mídia e no hipergênero}

Um exemplo particularmente interessante quanto às relações entre gênero, mídia e hipergênero é o da televisão. Ela apresenta toda uma complexa estrutura de suportes que vão desde a via de transmissão, aparelhos de gerenciamento, até os auditórios e mecanismos de captação dos programas. Sua produção contempla conjuntos de práticas relacionadas, por exemplo, à preparação, filmagem ou captação, e edição dos programas. Sua recepção envolve, entre outros, os aspectos do aparelho de tevê, que oferece certas possibilidades de interação na via analógica e outras na via digital. Sua organização se dá, primeiramente, a partir dos canais e, em cada um deles, por meio de hipergêneros (os diversos programas) e de gêneros (como as chamadas para programas). Existem gêneros e hipergêneros organizadores (vinhetas institucionais, chamadas, bastidores) e gêneros de funcionamento (a maioria dos programas). Nos comentários que se seguem, procuro aprofundar esse último aspecto (a organização), pois é aí que se evidencia, mais especificamente, a relação entre gênero, hipergênero e a mídia televisão.

Os canais são os principais componentes da organização dessa mídia e, como tal, coincidem com a própria mídia. Quando assistimos à televisão, assistimos, a um canal, que, por sua vez, apresenta toda uma organização específica, em termos de identidade visual, conteudística e ideológica. ${ }^{11}$ Vejase, por exemplo, a diferença entre o National Geographic e o Globo News.

$\mathrm{Na}$ televisão, a interação se faz com um interlocutor ausente, o que molda uma boa parte dos gêneros e hipergêneros que nela circulam. Se o programa é ao vivo, há uma organização da linguagem, se gravado, outra, se há auditório presente, ainda outra. A forma da organização e os modos de recepção da televisão, portanto, dependem bastante de quais suportes são mobilizados e das práticas de produção postas em marcha. Não obstante a essa variação, há, contudo, características que emergem como marcas próprias dessa mídia. A utilização de muitos close-ups na televisão, por exemplo, deve-se ao

\footnotetext{
${ }^{11}$ Uma relação parecida com a existente entre canais e a mídia TV pode ser verificada entre o jornal e seus cadernos ou entre um site e suas páginas.
} 
fato de o interlocutor estar interagindo com o programa mediante uma tela relativamente pequena (ou pelo menos esse ainda é o caso da maioria dos expectadores). Passemos a um exemplo dos gêneros que compóem o canal, no caso, a Rede Globo [QUADRO 3].

QUADRO 3

Grade de programas e gêneros postos em circulação no canal Rede Globo no dia 18 de setembro de 2008

\begin{tabular}{|c|c|c|c|c|c|}
\hline Horário & Programa & Gênero & Horário & Programa & Gênero \\
\hline 05:00 & $\begin{array}{l}\text { Telecurso Educação Básica } \\
\text { - Tecendo o Saber }\end{array}$ & Telecurso & $14: 40$ & $\begin{array}{l}\text { Vale a Pena Ver de Novo - } \\
\text { Mulheres Apaixonadas }\end{array}$ & Telenovela \\
\hline $05: 20$ & Novo Telecurso & Telecurso & $15: 40$ & $\begin{array}{l}\text { Sessão da Tarde Pequenos } \\
\text { Segredos }\end{array}$ & $\begin{array}{l}\text { Filme } \\
\text { (comédia) }\end{array}$ \\
\hline $05: 35$ & Telecurso Ensino Médio & Telecurso & $17: 21$ & Globo Notícia & Telejornal \\
\hline 05:50 & $\begin{array}{l}\text { Telecurso Ensino } \\
\text { Fundamental }\end{array}$ & Telecurso & $17: 24$ & Malhação & Telenovela \\
\hline 06:05 & Globo Rural & $\begin{array}{l}\text { Revista } \\
\text { eletrônica } \\
\text { (agrícola) }\end{array}$ & $17: 55$ & Ciranda de Pedra & Telenovela \\
\hline $06: 25$ & Bom Dia Praça & Telejornal & $18: 45$ & Praça TV - Segunda Edição & Telejornal \\
\hline $07: 15$ & Bom Dia Brasil & Telejornal & $19: 05$ & Três Irmãs & Telenovela \\
\hline 08:04 & Radar & $\begin{array}{l}\text { Boletim } \\
\text { informativo }\end{array}$ & $20: 00$ & Jornal Nacional & Telejornal \\
\hline 08:07 & Mais Você & $\begin{array}{l}\text { Revista } \\
\text { eletrônica } \\
\text { (feminino) }\end{array}$ & $20: 30$ & Horário Político & $\begin{array}{l}\text { Programa } \\
\text { eleitoral }\end{array}$ \\
\hline $09: 33$ & Globo Notícia & $\begin{array}{l}\text { Plantão de } \\
\text { notícias }\end{array}$ & $21: 00$ & A Favorita & Telenovela \\
\hline $09: 37$ & TV Globinho & \begin{tabular}{|l|}
$\begin{array}{l}\text { Revista } \\
\text { eletrônica } \\
\text { (infantil) }\end{array}$ \\
\end{tabular} & $22: 10$ & A Grande Família & $\begin{array}{l}\text { Série } \\
(\text { sitcom })\end{array}$ \\
\hline $12: 00$ & Praça TV - Primeira Edição & Telejornal & $23: 00$ & Casos e Acasos & $\begin{array}{l}\text { Série } \\
\text { (comédia) }\end{array}$ \\
\hline $12: 35$ & Globo Esporte & Telejornal & $23: 45$ & Jornal da Globo & Telejornal \\
\hline $13: 00$ & Horário Político & $\begin{array}{l}\text { Programa } \\
\text { eleitoral }\end{array}$ & $00: 15$ & Programa do Jô & $\begin{array}{l}\text { Programa de } \\
\text { de entrevista } \\
\end{array}$ \\
\hline $13: 30$ & Jornal Hoje & Telejornal & $01: 45$ & $\begin{array}{l}\text { Intercine Lenda Urbana } \\
\text { ou A Jurada }\end{array}$ & $\begin{array}{l}\text { Filme } \\
\text { (suspense) }\end{array}$ \\
\hline $13: 55$ & Vídeo Show & $\begin{array}{l}\text { Revista } \\
\text { eletrônica } \\
\text { (bastidores) }\end{array}$ & 03:50 & $\begin{array}{l}\text { Corujão } \\
\text { Crime Perfeito }\end{array}$ & $\begin{array}{l}\text { Filme } \\
\text { (drama) }\end{array}$ \\
\hline
\end{tabular}


Em um canal como a Rede Globo [como se pode verificar no QUADRO 3], circulam, em sua maioria, hipergêneros compostos por outros gêneros. Um telejornal, por exemplo o Jornal Nacional, é formado por vinhetas de abertura e de encerramento e por gêneros como a notícia, a reportagem, a entrevista, etc. ${ }^{12}$ Um programa de entrevistas, como o Programa do Jô, apresenta também vinhetas de abertura e encerramento, além da entrevista, de filmes curtos, competições, números musicais, etc. Um gênero produzido no interior desses hipergêneros ajuda a realizar a prática social para a qual o programa foi supostamente idealizado: relatar eventos sociais, no caso do Jornal Nacional, ou expor as opiniōes de convidados, no caso do Programa do Jô. ${ }^{13}$

Além desses gêneros (de funcionamento) que são o alvo principal da interação realizada pelo canal, a Globo apresenta também gêneros organizadores: vinheta institucional (a exemplo do plim-plim), marca d'água digital, chamada de programa e programa de bastidores (esse último, o programa Vídeo Show, organizado na forma de um hipergênero). Canais que não transmitem 24 por dia apresentam ainda vinhetas de abertura e encerramento da programação.

Um dos exemplos mais complexos e intrigantes dessa relação entre gênero, hipergênero e mídia, contudo, é a internet. Como mídia, ela compõe-se de diversos suportes físicos (cabo, modem, HD, monitor, etc.), é produzida pela manipulação da linguagem HTML (hypertext markup language, que possibilita a construção de conexôes hipertextuais), é recebida mediante formas específicas de interação usário / rede / usuário, e se organiza, por um lado, mediante o navegador e sites de busca (gêneros organizacionais) e, por outro, através de diversos tipos de sites (gêneros funcionais). $\mathrm{O}$ aspecto mais interessante com relação à internet, contudo, é que, nela, muitas outras mídias são mobilizadas

\footnotetext{
${ }^{12}$ No caso do jornal impresso, pode-se citar, entre outros, os seguintes gêneros que o organizam como hipergênero: o cabeçalho (indica o hipergênero); a chamada (indica o conteúdo do hipergênero); o expediente (indica os autores responsáveis); o editorial (fornece a opinião do / s autor / es hierarquicamente superior / es na cadeia de produção do jornal); a carta do leitor (expressa a opinião do coenunciador).

${ }^{13}$ Em uma leitura crítica desses hipergêneros, seja procurando vislumbrar as representaçōes discursivas na linha de Fairclough (2003), seja procurando determinar o projeto enunciativo na linha de Bakhtin (1953), é possível se determinar outras práticas sociais, inclusive de caráter ideológico (uma vez que os telejornais, por exemplo, em geral têm como pano de fundo a defesa não explícita de um ou outro grupo social).
} 
(por vezes, até mídia dentro de mídia), trazendo cada uma os seus gêneros e hipergêneros específicos. Vejamos um exemplo específico dessa relação.

A FIG. 2 permite visualizar uma versão antiga do site da Universidade do Sul de Santa Catarina, que se compõe na forma de um hipergênero. Uma marca do site como um hipergênero é a existência de um gênero específico (o menu geral) que permite acessar seçôes do site, outros sites, outras mídias, etc., e que funciona como um elemento unificador. Nesse exemplo específico, temos três menus fixos: acima, as informações sobre os serviços centrais da universidade (graduação, pós-graduação, etc.) e os campi (com imagens identificadoras); ao lado esquerdo, as informaçôes institucionais (sobre a administração, sobre o funcionamento dos serviços, etc.); e, abaixo, um menu com links para diversos sites que podem ser entendidos como os destaques da universidade. Ao centro dessa homepage, existem conteúdos temporários: anúncios, chamadas de notícias, links para páginas específicas, etc.

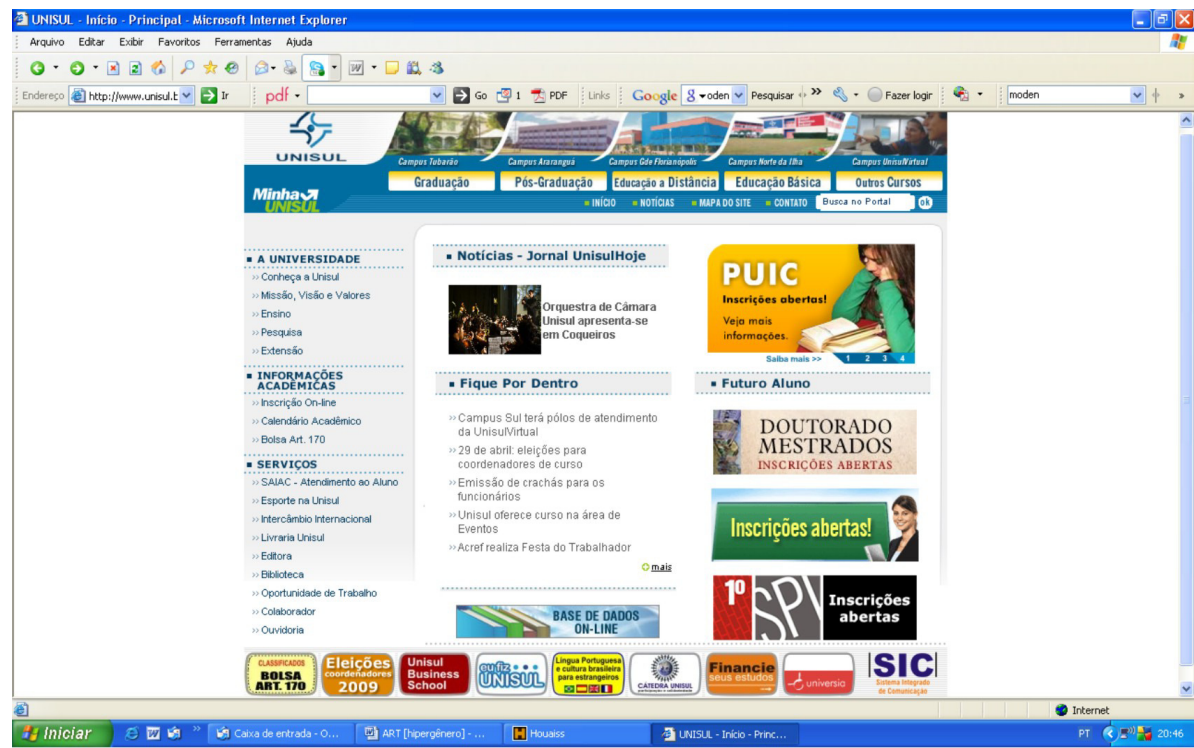

FIGURA 2 - Página principal do site da Universidade do Sul de Santa Catarina (www.unisul.br - 29/04/09)

Ao se clicar no item SIC (Sistema Integrado de Comunicação), que fica no menu inferior, tem-se acesso a uma seção do site da Unisul [FIG. 3]. Essa página mobiliza uma espécie de verbete que apresenta uma explicação institucional do que vem a ser o SIC. As seçóes do site, como essa página do 
SIC, compõem o site como um hipergênero. Cada seção realiza um enunciado, mas, ao mesmo tempo, no conjunto, elas formam um grande enunciado, que é o site institucional da Unisul. Essas páginas, por sua vez, apresentam menus secundários. Ao se clicar no item Unisul TV da página em questão, têm-se acesso à página do canal de televisão da Universidade.

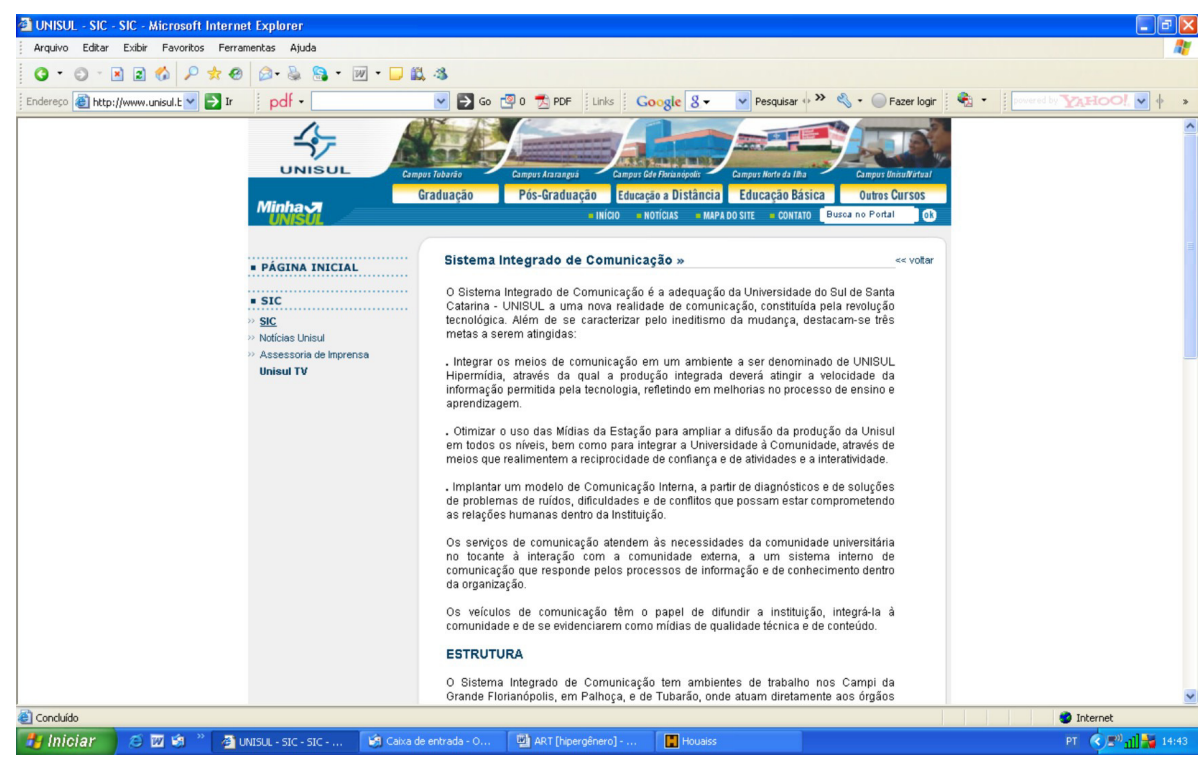

FIGURA 3 - Página principal do site do Sistema Integrado de Comunicação da Universidade do Sul de Santa Catarina (www.unisul.br/content/site/sic/index.cfm - 29/04/09)

Nessa página [FIG. 4], pode-se observar, além dos menus característicos, também a mobilização de uma outra mídia: o vídeo acessível mediante o programa Adobe Flash Player. No caso da FIG. 4, tem-se o acionamento de um gênero - uma entrevista - que circulou na tevê internamente a um hipergênero específico - o telejornal Câmera Aberta. Como mídia, o Adobe Flash Player possibilita um tipo específico de mediação de gêneros que funcionam em outras mídias (o cinema, a tevê, o vídeo amador, etc.) e de gêneros produzidos para a própria internet. No caso dos vídeos produzidos externamente à internet, a prática social realizada é a mesma da mídia original, porém com um incremento de possibilidades devido à recontextualização ocorrida. Ou seja, a entrevista do telejornal Câmera Aberta, quando circula no site, continua sendo uma forma de aportar informaçōes e opiniōes diretamente 
da fonte informativa, mas recebe um contexto interpretativo e funcional diferente, no qual mesmo o tempo do acesso e da leitura são diversos. ${ }^{14}$

A mídia internet se organiza e funciona basicamente por meio de hipergêneros: sites de busca, sites institucionais, dicionários e enciclopédias, páginas pessoais, blogs, etc. Em todos eles, podem ser introduzidas outras mídias: vídeo, e-mail, arquivo (pdf, doc, ppt, entre outros), chat, fórum, programa de conversação instantânea (p. ex., MSN), fotografia, áudio, etc. Algumas dessas mídias compõem-se de um único gênero componente: o chat e o fórum, por exemplo. O e-mail, por sua vez, corresponde a um gênero específico, mas, como mídia, permite a circulação de diversos outros gêneros e mídias. Ou seja, nós interagimos mediante gêneros e hipergêneros no contexto imediato de mídias que, por vezes, aparecem encadeadas.

Uma visualização mais aprofundada desses gêneros e mídias da internet exigiria um trabalho mais específico de levantamento e análise de dados. No caso dos gêneros aqui abordados, seria necessário um levantamento das açôes de textualização, produção e compreensão, bem como a determinação das práticas sociais que eles realizam, além de se explorar uma ou outra das relaçôes genéricas que os instanciam (hipergenéricas, midiáticas, sistêmicas, e comunitárias). Para uma explanação mais aprofundada das mídias aqui citadas (a televisão e a internet), também seria importante um levantamento mais pormenorizado das formas de organização, produção e recepção, bem como dos suportes que as compõem.

\footnotetext{
${ }_{14}$ Até alguns meses atrás, o programa era disponibilizado no seu todo no site da Unisul TV, o que produzia uma visualização mais enfática do que estou procurando demonstrar aqui. A leitura do site incluía, como opção, a leitura de todo um hipergênero proveniente de outra mídia.
} 


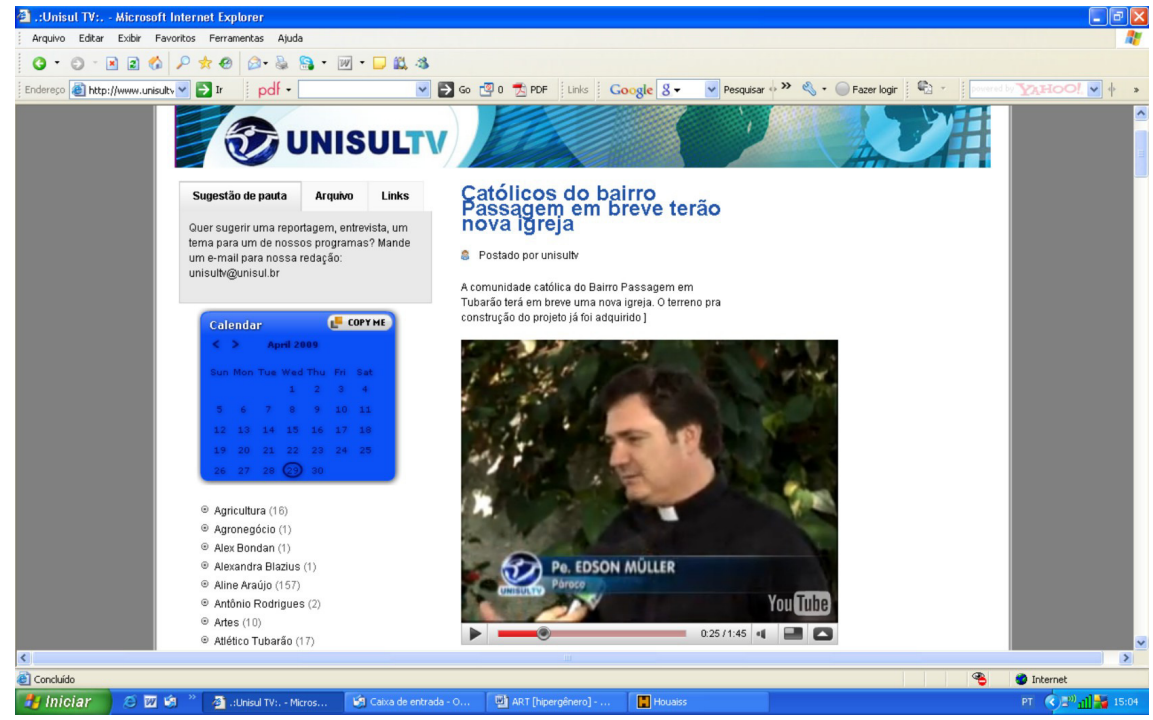

FIGURA 4 - Página principal do Site da Unisul TV (www.unisultv.com.br/ - 29/04/09).

O fenômeno da convergência das mídias revoluciona uma série de práticas sociais e cria novos funcionamentos para os gêneros tradicionais. $\mathrm{O}$ livro em arquivo pdf, por exemplo, traz uma série de gêneros para uma nova mídia, o que enseja todo um novo conjunto de ações de leitura. Na pesquisa em que se utiliza o livro em arquivo pdf (principalmente se ele estiver compondo um banco de livros online, como o Google Books), pode-se ir direto aos trechos que interessam, formando duas categorias de práticas de leitura: obras para ler no todo e obras para consultar (fazer levantamentos). Essas novas ações de leitura provavelmente irão produzir impacto nos gêneros centrais da ciência, como o artigo científico e a monografia, que poderão contar com um espaço maior para levantamentos e comparaçóes de conceitos.

\section{Considerações finais}

Neste artigo, procurei construir uma explicação para as relaçōes entre gênero / hipergênero, mídia / suporte. Propus que o suporte seja visto como um componente da mídia, passando essa a ser o contexto imediato do gênero (e do hipergênero).

Para pensar o significado dos três termos (gênero, mídia e suporte) propus, portanto, uma organização metodológica dos conceitos postos na área 
(passando por uma conceptualização de gênero e de relação genérica) que pode ajudar na reflexão sobre esses fenômenos e na proposição de pesquisas futuras.

Muito do que propus aqui não pôde ser aprofundado, pois tais detalhamentos não cabem nos limites de um artigo. São ideias que pretendo, contudo, explorar futuramente em outros trabalhos; quem sabe já com o retorno dos leitores deste artigo.

\section{Referências}

ASKENHAVE, I.; SWALES, J. M. Genre identification and communicative purpose: a problem and a possible solution. Applied Linguistics, v. 22, n. 2, p. 195-212, 2001.

BAKHTIN, M. Os gêneros do discurso. In: Estética da criação verbal. Tradução de Paulo Bezerra. São Paulo: Martins Fontes, 2006 [1953].

BAKHTIN, M.; VOLOCHÍNOV, V. N. Marxismo e filosofia da linguagem. 6. ed. Trad. Michel Lahud e Yara Frateschi Vieira. São Paulo: Hucitec, 1992 [1929].

BAZERMAN, C. Systems of genres and the enactment of social intentions. In: FREEDMAN, A.; MEDWAY, P. (Ed.). Genre and the New Rhetoric. London: Taylor \& Francis, 1994. p. 79-101.

BHATIA, V. K. Worlds of written discourse: a genre-based view. London; New York: Continuum, 2004.

BONINI, A. Critical genre analysis and professional practice: the case of public contests to select professors for Brazilian public universities. Linguagem em (Dis)curso, v. 10, p. 485-510, 2010a.

BONINI, A. Genres of receptionist / guest interaction in the hotel industry. Letras, v. 40, p. 133-145, 2010b.

BONINI, A. As relações constitutivas entre o jornal e seus gêneros: relato das pesquisas do 'Projeto Gêneros do Jornal'. In: BRAGA, S.; MORITZ, M. E. W.; REIS, M. S.; RAUEN, F. J. (Org.). Ciências da linguagem: avaliando o percurso, abrindo caminhos. Blumenau: Nova Letra, 2008. p. 21-45.

BONINI, A. A relação entre prática social e gênero textual: questão de pesquisa e ensino. Veredas (UFJF), v. 11, n. 2, p. 1-21, 2007. Disponível em: <http:// www.revistaveredas.ufjf.br/volumes.html>.

BONINI, A. Os gêneros do jornal: questões de pesquisa e ensino. In: KARWOSKI, A. M.; GAYDECZKA, B.; BRITO, K. S. (Org.). Gêneros textuais: reflexões e ensino. 2. ed. Rio de Janeiro: Lucerna, 2006 [2005: Editora Kaygangue]. p. 57-71. 
BONINI, A. Veículo de comunicação e gênero textual: noções conflitantes. D.E.L.T.A., v. 19, n. 1, p. 65-89, 2003. Disponível em: <http://www.scielo.br/ scielo.php?script $=$ sci_serial\&pid=0102-4450\&lng=pt\&nrm=iso $>$.

BONINI, A. Em busca de um modelo integrado para os gêneros do jornal. In: CAVALCANTE, M. M.; BRITO, M. A. P. (Org.). Gêneros textuais e referenciação. Fortaleza, CE: Grupo Protexto, 2004 [2001]. (livro em cd-rom)

CHARTIER, R. A aventura do livro: do leitor ao navegador. São Paulo, Editora da UNESP, 1997.

DEBRAY, R. Curso de midiologia geral. Petrópolis: Vozes, 1993 [1991].

DEVITT, A. J. Intertextuality in tax accounting. In: BAZERMAN, C.; PARADIS, J. (Ed.). Textual dynamics of the professions. Madison: University of Wisconsin Press, 1991. p. 336-357.

FAIRCLOUGH, N. Analysing discourse: textual analysis for social research. London: Routledge, 2003.

FIGUEIREDO, D. C. Como ser assertiva e politicamente correta na cama: Sexualidade feminina na revista Cosmopolitan. The ESpecialist, São Paulo, v. 15, p. 121-136, 1995.

FURLANETTO, M. M. O sujeito, o dizer, a interpretação: identidade em crise. Atos de pesquisa em educação, v. 2, n. 2, p. 207-229, maio/ago. 2007. Disponível em: $<$ http://proxy.furb.br/ojs/index.php/atosdepesquisa/article/view/576/522>.

GIDDENS, A. A constituição da sociedade. São Paulo: Martins Fontes, 2003 [1984].

HOUAISS, A.; VILLAR, M. S. Dicionário Houaiss da Lingua Portuguesa. Rio de Janeiro: Objetiva, 2001.

KLEIBER, G. Sens, référence et existence: que faire de l'extralinguistique? Langages, n. 127, p. 9-37, 1997.

McLUHAN, M. Os meios de comunicação como extensões do homem (understanding media). São Paulo: Cultrix, 2002 [1964].

McLUHAN, M.; FIORE, Q. O meio são as massa-gens: um inventário de efeitos. São Paulo: Record, 1969 [1967].

MAGALHĀES, C. M. Interdiscursividade e conflito entre discursos sobre raça em reportagens brasileiras. Linguagem em (Dis)curso, v. 4, n. esp.: 'Análise crítica do discurso' org. por C. R. Caldas-Coulthard e D. C. Figueiredo, p. 35-60, 2004. MAINGUENEAU, D. Diversidade dos gêneros de discurso. In: MACHADO, I. L.; MELLO, R. (Org.). Gêneros: reflexões em análise do discurso. Belo Horizonte: FALE-UFMG, 2004. p. 43-58. 
MAINGUENEAU, D. Análise de textos de comunicação. 2 ed. São Paulo: Cortez, 2000 [1998a].

MAINGUENEAU, D. Scénographie de la lettre publique. In: SIESS, J. (Ed.). La lettre entre réel et fiction. Paris: SEDES, 1998b.

MARCUSCHI, L. A. A questão do suporte dos gêneros textuais. Lingua, linguistica e literatura, João Pessoa, v. 1, n.1, p. 9-40, 2003.

PARÉ, A.; SMART, G. Observing genres in action: toward a research methodology. In: FREEDMAN, A., MEDWAY, P. (Ed.). Genre and the New Rhetoric. London: Taylor \& Francis, 1994. p. 146-154.

QUEM matou o carro elétrico? Direção e roteiro de Chris Paine, produção de Jessie Deeter. São Paulo: W Mix Distribuidora Ltda, 2006. 1 DVD (92 min.). Documentário.

SILVA, N. R. O gênero entrevista pingue-pongue: re-enunciação, enquadramento e valoração do discurso do outro. Dissertação (Mestrado em Linguística) Universidade Federal de Santa Catarina, Florianópolis, 2007.

SWALES, J. M. Research genres: exploration and applications. Cambridge: Cambridge University Press, 2004.

SWALES, J. M. Genre analysis: English in academic and research settings. New York: Cambridge University Press, 1990.

TÁVORA, A. D. F. Construção de um conceito de suporte: a matéria, a forma e a função interativa na atualização de gêneros textuais. Tese (Doutorado em Linguística) - Programa de Pós-Graduação em Linguística, Universidade Federal do Ceará, 2008.

Recebido em 14/04/2011. Aprovado em 03/08/2011. 